\title{
CAPABLE NZ: PERSEVERING TO SUCCESS
}

\section{Robin Day, Heather Carpenter, Glenys Ker and Phil Ker}

\section{INTRODUCTION}

Capable NZ is Otago Polytechnic's response to learning for adults in the workplace. Capable NZ, now regarded as a 'school' within the Otago Polytechnic organisational structure, a tertiary education provider based in Dunedin, New Zealand, has its origins as a centre for the assessment of prior learning - CAPL - a service set up to recognise the prior learning gained from experience which characterised adult learners. The limitations inherent in an assessmentonly service were soon recognised, leading to the establishment of unique alternative learning pathways to formal qualifications which now characterise Capable NZ.

The school, which embraces a Work-Based Learning (WBL) philosophy - i.e., learning at, for, and through work - has been the source of significant educational innovation for the polytechnic. At each stage of Capable NZ's development, new initiatives have been brought on stream to service experienced adult learners in the workforce and have significantly expanded the size and scope of the school. All of these initiatives have grown out of an increasingly deeper understanding of the nature and potential of work-based learning as a legitimate alternative approach to higher learning.

\section{HISTORY AND DEVELOPMENT}

\section{The New Zealand Context}

Otago Polytechnic's Capable NZ has its origins in the recognition of prior learning (RPL) 'movement' which emerged in New Zealand as a serious educational process in the late 1980s, following widespread international interest in work coming mainly from Britain and America, with activity also in New Zealand, Australia and Canada. Otago Polytechnic has come a long way in both understanding and applying RPL processes to meet learners' needs, and we have much to learn from reflecting on our own experience (Day in Evans, 2000).

Nancy Mills, of the New Zealand Qualifications Authority (NZQA), has described the economic advantages of RPL in New Zealand for a wide range of businesses in a variety of areas, including partnering with education providers, upgrading skills, reducing training costs and providing opportunities for advancement (Cohen \& Whitaker, 1994). Mills also identified the opportunities for those disadvantaged in terms of access to education, including Māori, women, disabled and rural peoples, recognising the benefits accruing from providing new and innovative pathways and opportunities for social change.

In 1991, the increasing numbers of mature students enrolling in tertiary education in New Zealand led the NZQA board to endorse the recognition of prior learning, sparking widespread national interest and the emergence of research and leadership, initially led by NZQA. Early developments generated considerable debate throughout the tertiary sector, with several vocational education providers carrying out a wide range of initiatives, including the use of the portfolio method for assessing prior learning at the University of Canterbury (Sheehan, 1992). The 
Nelson Polytechnic undertook initiatives around the development of policy guidelines for RPL as well as hosting a workshop in 1992 led by Julie McDougal and Colin Gunn, which was followed in April 1993 with an international RPL conference led by the NZQA (NZQA, 1993b).

Early RPL influencers were Robin Day (a future deputy chief executive) at Otago Polytechnic, who had begun doctoral studies in RPL in nursing education based at Otago Polytechnic, and Phil Ker (a future Otago Polytechnic CEO) who undertook a study examining the implementation of procedures and issues arising from a pilot programme conducted at the Auckland Institute of Technology (Ker, 1993). Glenys Ker (Hodges) and Phil Garing were instrumental in implementing RPL processes at Aoraki Polytechnic. An influential study by Jenny Harre Hindmarsh,Victoria University of Wellington, described the place of RPL in establishing advanced standing for special admission to graduate programmes in New Zealand university education (Cohen \& Whitaker, 1994).

A significant leading contributor to the ongoing RPL discourse was Nena Benton, of the New Zealand Council for Educational Research, who identified that the opportunities for assessment of prior learning (APL) would be an attractive option for learners who were disadvantaged by existing education structures. Her approach was reflective of humanistic and critical theory positions widely discussed in learner-led higher education aligned to the work of Michael Apple (Apple, 1979) and the constructs of discourse, knowledge, education and power; the work of Paulo Freire in his Education for Critical Consciousness (Freire, 1994); and the emancipatory promise of critical theory through the writing of Jurgen Habermas (Habermas, 1968).

Benton's contribution was notable in her work over a decade, culminating in the 7th Conference of the International Consortium for Experiential Learning:Te Rito o te Mātauranga: Experiential Learning for the Third Millenium, held in Auckland in December 2000 (Benton, 1991; Benton, 2000). This was a significant developmental milestone for assessment of prior learning in New Zealand, attended by international proponents of APL, key stakeholders and those actively engaged in the formative evolution phase of RPL practices from within New Zealand.

Early concerns surrounding RPL in New Zealand focused on standards, procedures and processes, raising valid questions around who sets assessment standards, quality assurance processes, the effectiveness and use of assessment methods, and the administrative support and systems needed for successful assessment outcomes. In the New Zealand context, NZQA worked to enable RPL through changes brought about within the 1990 Education Amendment Act requiring NZQA to take responsibility for recognition of competency already achieved through policy development of the National Qualifications Framework (NZQA Policy Statement, 1993a).

\section{RPL at Otago Polytechnic}

At Otago Polytechnic, a small academic team, including Academic Manager John Fletcher and Robin Day, led the introduction of an APL policy in 1993 (Academic Board paper cited in Day, 1997). This team, along with others, worked to embed robust RPL policy, procedures and processes and to establish an organisational culture that embraced recognition of learning wherever and however it occurred. The polytechnic was supported and guided in this work by international experts, including Urban Whittaker, representing the Council for Adult and Experiential Learning (CAEL), and Ruth Cohen of the International Council for Experiential Learning (ICEL).

Core academic standards developed at Otago Polytechnic were based on CAEL's espoused principles. They reflected the core value that credit only be given for the learning gained from experience rather than the experience itself, which may form the basis of evidence for assessment. Credit awarded must be appropriate to the level of learning, and the balance of learning between theory and practice, for the qualification under consideration. Credit awarded must be determined by relevant subject matter experts, and that credit should be appropriate to the context in which it is granted. Appropriate administrative standards must ensure that credit is not awarded for the same learning more than once - commonly termed as double-dipping. Policy must include processes that allow for appeals and be clearly promoted to learners. Fees should be based on services delivered rather than credit awarded. 
A critical area of policy required that all staff involved in the assessment of prior learning be trained and have the opportunity to develop an in-depth understanding of prior learning assessment, as it differs significantly from traditional assessment practices. Ongoing monitoring and review are critical to ensure currency and relevancy of all practices and to provide essential feedback - especially from learners, key stakeholders, industry and faculty - on the effectiveness of RPL practices and in their meeting of educational and social needs. These core policy framework principles remain today, with ongoing oversight in place through an established Capable NZ academic committee which reports to the polytechnic's academic board.

Following an extensive development phase in New Zealand for the recognition of prior learning, in 1999 the then chief executive of Otago Polytechnic and the academic board agreed that The Centre for Assessment of Prior Learning (CAPL), later rebranded as Capable NZ, be established. CAPL emerged from a pilot project involving the tourism sector and the industry training organisation through an initiative entitled Job Shop, part of the polytechnic's tourism department's activities at the time.

The early days of CAPL saw small numbers of assessments successfully conducted in limited areas. Considerable effort was made to establish a broad base of application across the polytechnic, with new offerings including credit arrangements for Registered Nurses wishing to upgrade their certificate and diploma qualifications to degree status by completing additional academic work; the Job Shop initiative in the tourism and hospitality areas; and a developing area of interest from experienced learners seeking applied management qualifications at degree level. Although growth was modest, Otago Polytechnic broadened its availability to learners across the country through a New Zealand-wide Centre for Assessment of Prior Learning, established with other providers. Christchurch Polytechnic Institute of Technology joined the movement, also launching a successful CAPL centre.

During the early development phase, CAPL created systems and procedures to ensure quality assurance and effective delivery through all processes, including initial contact with learners, portfolio workshops, staff training, the potential role of technology, assessment methodologies and reporting. This included an assessment model designed to strengthen quality assurance standards, which focused on six broad constituents: Currency, Relevance/ Repeatability, Authenticity, Verifiability/Validity, Equitability and Sufficiency (CRAVES) (Day \& Devjee, 2000).

In 2004 a new chief executive for Otago Polytechnic was appointed. Phil Ker was an avid proponent of RPL. His leadership cemented the strengthening of CAPL under the direction and guidance of the chief executive and deputy chief executive over subsequent years. However, the growth of CAPL continued to be slow. While the opportunity to engage in the process of having prior learning recognised was valued, feedback from learners identified that the process was time-consuming, too complex, didn't fit well with employment demands and lacked engagement. At that time, the assessment processes were based on curricula driven by Bloom's taxonomy (Bloom, 1956) and on the assessment of taught courses, which required that all learning outcomes must be met through an extensive evidence base.

\section{Early experimental methodologies}

In the beginning, learners were subjected to a range of processes - for example, challenge testing - and completing additional academic work to fill any identified gaps in knowledge. They completed arduous processes involving extra assignments to assess academic writing skills, and examinations within timeframes that would never have been required of a comparable group of taught students. Compounding these challenges was the requirement to compile extensive collections of evidence alongside the already substantial professional and personal commitments typical of adult learners. This approach did not fit well with developing principles of adult learning based on humanistic, learner-centred approaches or critical theories that considered the opportunity to address the learner needs of disadvantaged groups, resulting in disengagement and disincentives to adopting the learner-focused models that had shown earlier promise. 
The Otago Polytechnic experience was consistent with findings reported elsewhere internationally, with barriers to access to RPL reflecting resistance from academic assessors. They were reluctant to award credit for courses that had not been taught. Faculty also continued to prefer using the traditional methods of assessment with which they were familiar and used with taught students. The key area of tension that was evident was the apparent mismatch in the use of traditional assessment methods rather than seeing portfolio assessment as the central RPL process. Even with portfolio assessment, the early approach was to require evidence of each and every learning outcome for a course, taking a deficits approach rather than focusing holistically on the strengths of the evidence presented.

Thus, the promise of RPL - meeting the needs of second-chance learners, of those disadvantaged by traditional education, of women and indigenous peoples, and those wishing to return to the workforce - was far from being realised. Learners were left feeling disenfranchised, and it was clear that a new direction was needed.

\section{A redeveloped assessment model}

However, changes were emerging in the traditional approach to assessment at this time, and academic work encouraging a constructivist learner-led view, using tools such as storytelling and narrative, was being undertaken by Otago Polytechnic staff members Janice McDrury and Maxine Alterio. They demonstrated how formalised storytelling processes and reflective practice could be used to advance professional practice (McDrury \& Alterio, 2002).This sat comfortably with the concept of professional assessment conversations being part of the assessment of prior experiential learning.

Otago Polytechnic rose to this RPL assessment challenge. The curriculum model in place nationally required all programmes of learning to explicitly state programme aims and learning outcomes at all levels, providing a coherent road map linking course-level aims, assessments and outcomes to year-level outcomes and overall graduate profile statements. Around 2004, an opportunity was identified whereby through a robust and refocused portfolio development assessment process, the portfolio could be mapped against the graduate profile outcomes that were in place at a programme level. The graduate profile was recognised as the outcome level that a taught student would achieve, having competed a prescribed pathway of learning. It was considered that through a robust RPL facilitation process and assessment, the same level and awarded credit value of learning from experience could be identified, meeting all requirements of rigour and academic quality.

A trial process was undertaken with a single learner working with CAPL staff to develop a portfolio to test this new approach. The portfolio was assessed by a panel comprising an expert in RPL assessment, a subject matter expert (SME) with academic seniority for the relevant qualification, and an external industry panel member (SME from industry). The candidate presented the portfolio to the panel in person in an extended assessment interview, and it was evident that the candidate exceeded all areas expected in the graduate profile.

Following this trial, the portfolio assessment methodology was refined, and the practice of candidate presentation to an appropriately experienced assessment panel (as above) was adopted. A reporting mechanism was established that linked the learning as evidenced to the graduate profile outcomes, creating an audit trail of the assessment decision process. Concerns were raised over knowledge gaps and, as is the case with traditionally taught learners, not all learners achieve the highest possible grades in all assessments all of the time. The expectation of RPL learners should not be any different. Critical skills were identifiable and must be met by both taught and RPL learners. The effect of these developments was a significant acceleration in candidate numbers over the following years, with the portfolio method being further refined and developed into the model used today.

\section{A successful and credible model}

An authentic learner-led process that could even begin to meet the expectations of the diversity of adult learner needs and circumstances, along with the delivery systems and appropriate quality processes, is a very tall order to fulfil - but Otago Polytechnic has indeed filled the bill. 
Otago Polytechnic's model is grounded in a well-articulated educational philosophy with a clear focus on the learner. This is evident in the contributions provided throughout this edition of Scope, whereby through careful attention, the learner is placed as the centre of the process. Learner-centricity has been complemented by the evolution of creative approaches such as the use of advanced standing for the award of credit, a highly sophisticated facilitation process providing for outstanding learner engagement; the use of narrative; and a focus on strengths and capability rather than on learner deficits. Where learners have significant knowledge or capability gaps, requiring additional work, a new learning exercise is put in place.

All of these initiatives place the learner as the core driver of their learning and what they report as a transformative educational experience that has made a significant difference in achieving some of the potential promises of the early vision offered by RPL.

\section{Lessons learned}

Our major lesson learned at that time was to keep sight of the original RPL vision and not become distracted by those constrained by and adherent to traditional educational practices. It is, therefore, important to continue the valuing of learning through experience, accepting that this can evolve through life and work; and to place the learner at the centre of both learning and assessment to enable a truly transformative educational experience.

\section{FACING THE CHALLENGES AND EXPANDING CAPABLE NZ}

In the early twenty-first century, work-based learning had become increasingly important globally throughout a time of workplace change, serving to broaden participation in higher education. The opportunity to value and credit learning for, at and through work, and the greater emphasis on self-management and self-design of learning led to the development of professional practice qualifications - programmes of learning that enabled practitioners to take a critical, reflective and evidenced-based approach to change and to develop at work. Otago Polytechnic, through Capable NZ, developed these opportunities for New Zealand and practitioners in the New Zealand tertiary environment. As their work developed and matured into a more complete understanding of work-based learning, Capable NZ transitioned itself from an initial role as an assessment centre to an academic school. The school expanded its provisions by utilising work-based portfolio and professional practice methodology in a new era of professional practice degrees and graduate diplomas.

The Master of Professional Practice (MProfPrac or MPP) was established in 20 I2, strengthening Otago Polytechnic's provision of qualifications at postgraduate level. The Master of Professional Practice was an innovative approach to postgraduate qualifications, providing a multidisciplinary pathway of considerable benefit to both the learner and the polytechnic. The learner had greater scope and flexibility, was able to undertake real work projects and integrate work, theory and practice. This development aligned with the strategic intent of Otago Polytechnic in providing postgraduate provision in the advanced practice space areas for vocational education, and in encouraging an expansion of the personalised learning approach that was seen as the future landscape of tertiary education. It allowed learners to build their capabilities on the job, and in areas of benefit to their employers.

Mature, experienced and skilled learners began to use their knowledge, skills and experience to explore the issues and challenges of their own workplaces; these became their curriculum, and the process served to stimulate a new awareness of professional growth and identity. A professional practice focus was captured in the learner-centred approach of the MPP, providing a credential that is self-designed, self-directed and involves self-managed study by the learner, and is targeted to the particular practice of the learner. Facilitation and academic mentoring roles developed to work with the unique requirements of the learner, as well as mentor and teach academic skills. Since its introduction as a postgraduate degree, Capable NZ has seen 91 learners graduate through this programme. 
The Graduate Diploma in Professional Practice (GradDipProfPrac) was developed at the same time, providing an opportunity for learners to develop work-based projects at Level 7. The New Zealand Institute of Safety Management chose this qualification as the vehicle for benchmarking graduate status as a health and safety professional. Thus began a programme provided for health and safety practitioners around New Zealand to upskill this group in response to the new government regulations in the Health and Safety at Work Act (20I5) and in the aftermath of the Pike River tragedy; over 38 learners have since graduated.

These were years of expansion into the wider New Zealand professional communities in a range of areas. Child Youth and Family chose Capable NZ as the school to credential family group conference co-ordinators through a Level 7 programme named Validating Quality Practice. Heather Carpenter and Glenys Ker developed the programme and travelled the country in 2015, providing workshops to over 170 FGC co-ordinators, following up with liaison and assessment of their portfolios. Feedback from the co-ordinators strongly validated the Capable NZ process, noting a new confidence and a clear strengthening of professional identity arising from self-assessment of practice. Many of these family group co-ordinators went on to complete either the Bachelor of Social Services or Bachelor of Applied Management.

At the same time, the Capable NZ process was also being used to respond to new regulations in the building industry. John Gualter undertook extensive travel around New Zealand to provide workshops for council building inspectors and to assess their work. In the early days, hundreds of hard-copy portfolios were shipped to the Capable office in Dunedin in Eastlight folders for assessment, until John transitioned this process into the digital age. Over 600 building inspectors were credentialed via two qualifications, the National Diploma in Building Control Surveying (Small Buildings), at Level 5, and Large Buildings (Level 6).

The underlying foundation qualification offered by Capable NZ was then - and continues to be - the undergraduate Bachelor of Applied Management degree, offered in a range of majors. The qualification evolved, growing in reputation and rigour as facilitation and assessment practice developed. Organisations such as the RNZAF and the NZDF became consistent users of the Bachelor of Applied Management, customising its requirements for over 50 learners developing their management and leadership skills. Throughout this time, Glenys Ker led the provision of the degree to sporting organisations including the Auckland Blues, Highlanders, Hurricanes, NZ Cricket, Silver Ferns, NZ Hockey and NZ Football (soccer), as well as to individual athletes, providing an avenue for professional growth and career development for many.

These work-based qualifications have provided academic staff at Capable NZ with opportunities to develop expertise in facilitation for academic practice. Facilitators and academic mentors have been required to adopt a different, broader and more holistic appreciation of the ways in which people learn in the WBL process. The process has also afforded academic staff at Capable NZ the opportunity to become familiar with the professional practice and cultures of the workplaces of their learners, and to develop relationships with the networks of stakeholders who are experts in industry, local government, the military, iwi and community and sporting organisations.

Over this period, Professor Jonathan Garnett, former director of the Institute for Work Based Learning at Middlesex University, and emeritus professor of Middlesex University, has regularly visited Otago Polytechnic as the monitor for the MPP, and to mentor and provide guidance for our programmes. We have learned and will continue to learn from the Middlesex experience; their work, research and philosophy provided the model for us, and our development has continued much of this alignment.

\section{What did we learn from these years?}

Progress so far has taught Capable NZ many lessons - not the least of which is that the distinctive skills and knowledge required to support learners at all levels must be derived from an accurate understanding of the model and philosophy utilised. This model has often appeared to be under threat from misperceptions of philosophy and 
practice. A clear understanding of the model can be lost in enthusiastic practice, and years of persistence have been required to retain the clarity that is transformative to learners and the rigor that is vital to the integrity of our qualifications. Training of facilitators and academic mentors remains critical to the success of our approach.

Above all, we have learned that the Capable NZ work-based learning model has been utilised successfully and appreciated greatly by our learners in a range of industries. Many of these learners have provided significant feedback on the transformative value of the process to their work, career development and their professional identity.

\section{REFINING CORE PRACTICE: LEARNER JOURNEYS AND FACILITATION}

In the early years, the core process of Capable NZ was centred on learning portfolios based on RPL principles. The then CAPL targeted highly experienced learners who had very few gaps in their knowledge and skills in relation to their chosen degree. Hence, the assessment approach worked well, because any gaps in knowledge that were identified were easily filled by self-study.

However, it was soon recognised that this assessment approach was not realising the potential of the individual learner and was denying opportunities to those with plenty of professional experience, but with more substantial knowledge and skill gaps. It became clear that more people could be supported to achieve degrees by acknowledging prior learning through a learning model rather than an assessment model. The essence of a learning model is critical reflection on experience, whereas the earlier assessment model focused almost entirely on compiling a portfolio of evidence to match the learning outcomes of the chosen degree.

Thus started the evolution of the approach which by 2014 would be known as the Independent Learning Pathway (ILP), an intensely reflective process which helped learners identify the experiences that had shaped their practice, extract the learnings from those experiences, and make sense of those learnings through the development of a framework of practice. At the same time, the evidence for meeting the graduate profile of the degree was brought to the fore through structured learning tasks.

These flexible learning opportunities enable people to achieve qualifications that meet their needs with regard to both what is learned and how it is learned, as well as addressing the emerging preference for people to undertake learning in their workplaces. The ILP approach was developed to focus on the individual learner who can commence their learning at any time, working one-on-one with a facilitator who is most suited to their area of interest. ILP learners are typically experienced adults in the workplace who do not have credentials, but who have wellestablished transferable skills, as well as substantial industry knowledge and specialist skills.

The ILP reflective process underpinned a different approach to degree learning from that typically undertaken in a taught degree. It is acknowledged that developing skills in critical reflection is also expected of students undertaking taught degrees; however, for the ILP, the learning process is based on critical reflection. Other key outcomes of degree-level learning are skills in analysis, enquiry, communication and an ability to engage with the literature. All these skills were strengthened progressively as the ILP approach was developed, and all became integrated into tasks required in portfolios of evidence. These tasks included new learning requirements which were introduced into portfolios to extend and develop learners further at graduate levels.

The beliefs that underpin the ILP approach can be summarised as follows:

- Where and how people learn is of itself not important to achieving a degree. It is the learning that counts.

- Well-motivated and experienced adult learners are capable of taking responsibility for and managing their own learning once expectations are made clear, and the required learning skills are developed.

- While critical reflection is the driving force of independent learning, this capability often needs to be developed, which is one of the essential roles of the facilitator. 
At the heart of this pathway is the facilitation of learning - and the role of the facilitator is essential to learner success (Ker, 2017). This is because experienced adults do not always have well-developed reflective capabilities - and they need to be guided to acquire quite sophisticated reflective skills if they are to make sense of their substantial learning from experience (Hall, 2002).

As the role of the facilitator developed with the evolution of ILP requirements, and then the introduction of professional practice degrees, the understanding of facilitation processes and skills became more important. In 2014 Glenys Ker began a Doctorate in Professional Practice with the University of Middlesex, the home of workbased learning, researching facilitation and independent learning. Her work provides a key resource for the ongoing knowledge and understanding needed to advance facilitation practice within Capable NZ.

Over time, it has become clear that effective facilitation of independent learning is not a simple set of technical tasks that are easily obtained. Our experience in Capable NZ has been that good facilitators of independent learning require high levels of skill, are not easy to find, and take considerable time to develop. As the skill levels of both the facilitators and the programmes have increased, so has the alignment of the facilitation process with professional standards.

\section{Facilitation as a professional activity}

As professionals, facilitators work within a recognised body of knowledge, within an ethical framework and with their learners' interests foremost. They exercise meaningful judgments about their learners, so they need themselves to be highly reflective and well-informed by the current body of knowledge about their profession. They are expected to acquire a repertoire of specialised techniques and knowledge, including knowledge of when to use a particular facilitation technique. Implicit in this conception of facilitation is the view that any problems in facilitation or learning can be solved given the skills, knowledge and expertise the person has in this area. Facilitators must define and enforce their standards of practice, which align with the 'facilitation of learning' model - i.e., autonomy, self-discipline and a shared ethic of performance. Facilitation is a professional activity, with facilitators having a significant degree of control over their work regarding the structure and the nature of work tasks. Facilitators have a pivotal responsibility to make their decisions in the best interests of their learners.

Within a professional approach to facilitation, there is very little procedural prescription, and the emphasis is focused on the abilities of the facilitator to help their learners to engage in the deep reflection which leads to transformational learning and understandings of new identity. The motivation for facilitators and learners to continue to improve their practice will come from within the facilitators and learners themselves, and not by standardised rules.

\section{A FUTURE FOR CAPABLE NZ}

Capable NZ has been a wellspring of educational innovation for Otago Polytechnic, with the most recent of these innovations being the suite of professional practice qualifications developed in direct response to learner needs and expectations. As people completed their Independent Learning Pathway (ILP) and achieved their degrees, they were highly motivated as a result of the learning which was drawn from their workplaces and their broader experiences, leading to a thirst for more of the same. The same, that is, in terms of the workplace as the source of their learning and their experience as the force that gave shape to that learning. The professional practice qualifications enable learners to broaden or deepen their capabilities through learning at an advanced level - Masters and then Doctorate. Of course, there is the Graduate Diploma in Professional Practice, which is a vehicle for new learning for people seeking a targeted undergraduate professional practice qualification. 


\section{What next?}

Capable NZ has until now focussed almost exclusively on a relatively narrow range of undergraduate degrees through the ILP approach and postgraduate qualifications through the two professional practice programmes, Master of Professional Practice and Doctor of Professional Practice. For the future, we can expect to see a broadening of the programme offerings to encompass potentially all vocational areas, with the probable exception at the undergraduate level of qualifications for the regulated health services, which are problematic in terms of licensing requirements.

There will be growth in Capable NZ at lower levels of the qualifications framework - the concept of 'a learner for life' will be embraced by the school as it introduces ILPs at both certificate and diploma level in a range of vocational areas where there is a qualification structure that scaffolds learning as workers develop their expertise. At certificate level, learners in the workplace who have acquired the necessary skills and knowledge of their chosen vocation over a three-to-four year period of full-time work will be appropriate learners for an ILP at Level 3/4 on the New Zealand Qualification Framework. Those same learners, with another three or four years of experience and who take on more responsibility and/or develop additional skills, can then realistically apply the same methodologies to achieve a Level 5/6 diploma and then, in due course, progress to a higher degree.

Capable NZ will develop more targeted professional practice qualifications for people who are wanting to develop specialist knowledge and capability sets - for example, in emerging careers such as sustainable practice. These qualifications will be at both undergraduate and postgraduate level and will focus on qualifying people within a practice area rather than extending practice, as is the case currently with these programmes of learning. As with current professional practice qualifications, learning will be project-based and will be for those able to learn independently.

We can also expect to see the development of much shorter professional practice qualifications - micro-credentials - which will address emerging skill areas in an increasingly dynamic employment environment. Professional practice micro-credentials will enable people to quickly adapt to changing workplace needs and expectations - for example, resulting from technological developments, radically different competitive environments or major legislative changes.

Not only will Capable NZ expand its programme portfolio as outlined above, but the school will also develop international markets, delivering both ILP and professional practice qualifications. Initially, these markets will be in English-speaking countries such as Australia, Canada and the Pacific Islands, where the vocational education systems are broadly similar to New Zealand. However, there is also considerable potential to offer the same programmes in Asian countries where New Zealand qualifications are held in high regard, acknowledging that there is a greater complexity and more challenge in contexts where teaching is privileged over learning and where learners are often passive recipients of received wisdom rather than active agents in their own learning. However, even in these constituencies there is an emerging realisation that the approach to teaching and learning needs to change if graduates are to be more effective in the workplace.

Capable NZ has had a transformative impact on the work and personal lives of most of its learners, many of whom have made significant advances in their careers after becoming qualified through the enhanced confidence which successful learning brings. These learners, now a significant alumni group, constitute a significant market for a wide range of support services, which can provide further support for career enhancement. These services will have reflective practice in common with the qualifications offered by Capable NZ and will enhance career prospects beyond the benefits which typically flow from holding a credential at the appropriate level. There are at least two significant services waiting to be developed and which have very high potential for uptake, not only by Capable NZ alumni, but also by the many others who are seeking career advancement.

The first of these services is in work/career coaching. There is no doubt that effectiveness in any role can be significantly enhanced if one is challenged to reflect on one's actions in the job, to ensure that experiences good and bad are learned from, and that more effective practice is adopted for the future. It matters not if the reflection 
is on something that has gone horribly wrong. Deep understanding of what did go wrong is what will ensure better decision-making in the future (Hall, 2002). Equally, careers often accelerate when people focus on the things that they are doing very well - although those who are expert in their fields often don't take the time to figure out what it is that is making them successful and how they could be even more so. Work coaching is what will provide the necessary support here.

The second set of services, complementary to the first, will be centred on helping people obtain deep and accurate self-knowledge and understanding as the basis for well-focused development plans. To secure this self-knowledge, there are a range of strategies including insight through inventories such as Myers-Briggs Type Indicator, as well as feedback through 360-degree feedback processes which Capable NZ can design, implement and provide debriefing support for. However, enhanced self-understanding will go nowhere without a sound development plan, for which Capable NZ can offer design, monitoring and support services.

Thus, the future of Capable NZ is as a career partner for life, supporting learning and development in the workplace - a comprehensive range of services for credentialing, new practice-based learning, self-understanding and enhanced effectiveness.

The late Dr Robin Day was an emeritus member of Otago Polytechnic with extensive experience in education and a passion for open learning, including assessment of prior learning. Robin had a strong history of leading initiatives in these areas at Otago Polytechnic and nationally throughout New Zealand, as well as international work in APL. Robin held roles that included teaching through to a significant period as deputy chief executive at Otago Polytechnic and had been a past holder of a Commonwealth of Learning chair in OER. Until his death in September 2020, he worked as a consultant and lead assessor for Capable NZ.

Dr Heather Carpenter is an education and careers consultant with extensive experience in tertiary education in areas of transition, teaching and learning, assessment, management and student services. Her interest and work over 12 years in Capable NZ is driven by its innovative broadening of accessibility of tertiary education and achievement for learners, and the fostering of transformative success through work-based learning. Heather is the author of two books in her specialist careers field and is an honorary life member of CDANZ. She currently works as a consultant and lead assessor for Capable NZ.

Dr Glenys Ker is a facilitator and assessor for both undergraduate and postgraduate programmes in Capable $\mathrm{NZ}$, as well as programme leader for undergraduate programmes. She has extensive experience in the secondary, polytechnic and university sectors as an educator and career practitioner and has worked for Capable NZ since 2005. Glenys undertook her doctorate in Professional Studies (Adult Learning) through Middlesex University to learn about professional practice qualifications in order to bring that knowledge to Otago Polytechnic. Through her doctorate, she developed a model for effective facilitation, drawing on the learning journeys of over 460 learners, including the personal and professional impacts of their learning and the role of the facilitator in that process. Glenys was awarded an honorary life membership of CDANZ for her leadership in the profession.

Dr Phil Ker is the former chief executive of Otago Polytechnic, leading the institution from 2004 to 2020. Phil's education career in both polytechnic and university settings included diverse roles, from teaching and staff development to leadership of both academic and service departments, prior to taking up his chief executive position. A particular passion has been the recognition of prior learning, starting with the establishment of an RPL service at Auckland Institute of Technology in the early 1990s. Phil's interest naturally led to his enthusiasm for new approaches to education for adult learners in the workplace, and to his contributions to a range of work-based learning initiatives at Otago Polytechnic, including independent learning pathways to traditional degrees and a range of professional practice qualifications. Phil is an academic mentor for Capable NZ, supporting professional practice masters and doctoral learners. 
Apple, M.W. (1979). Ideology and curriculum. London, UK: Routledge and Kegan Paul.

Benton, N. B. E. (199I). Recognition of prior learning: From hegemony to symphony. Wellington, NZ: Maori Caucus of the New Zealand Council for Education and Training in the Social Services.

Benton, R., \& Benton, N. (Eds.). (200 I). Te Rito o te Mātauranga: Experiential Learning for the Third Millennium. Selected Papers From the Seventh Conference of the International Consortium for Experiential Learning, Auckland, Aotearoa / New Zealand, December 4-8, 2000. Auckland, NZ: James Henare Maori Research Centre for the International Consortium for Experiential Learning.

Bloom, B. S. (Ed.). (1956). Taxonomy of educational objectives: The classification of educational goals. Handbook I: Cognitive domain. New York, NY: David McKay.

Carpenter, H., \& Ker, G. (2017). Learning from experience: Exploring professional identity growth through work-based learning processes. Scope (Flexible Learning), 2(2007-2017), 22-32.

Cohen, R., \& Whitaker, U. (1994). Assessing learning from experience. In M. T. Keeton (Ed.), Perspectives on experiential learning: Prelude to a global conversation about learning (pp. 35-53). Chicago, IL: Council for Adult and Experiential Learning.

Costley, C., \& Stephenson, J. (2008). Building doctorates around individual candidates' professional experience. In D. Boud \& A. Lee (Eds.), Changing practices of doctoral education (pp. I7I-186). London, UK \& New York, NY: Routledge.

Day, R. (1997). The recognition of prior learning: A case study of an undergraduate nursing degree programme [Unpublished PhD thesis.]. The Flinders University of South Australia.

Day, R., \& Devjee, F. H. (2000). Otago Polytechnic's experience in establishing a centre for assessment of prior learning (CAPL). Paper presented at the 7th International Conference on Experiential Learning (ICEL), Auckland, NZ.

Day, R. (2000). Commentary. In N. Evans (Ed.), Current APEL policy and practice in English higher education in the context of RPL around the world. (pp. 83-87). Higher Education Policy 52, Jessica Kingsley Publishers.

Freire, P. (1994). Education for critical consciousness. New York, NY: Continuum. (Original work published 1973).

Habermas, J. (1987). Knowledge and human interests (J. Shapiro, Trans.). Cambridge, UK: Polity Press. (Original work published 1968).

Hodges, G., \& Garing, P. (2003). Implementing a pilot programme for RPL.Timaru, NZ: Aoraki Polytechnic.

Hall, D.T. (2002). Careers in and out of organisations. Los Angeles, CA: Sage Publications

Ker, G. R. (2017). Degrees by independent learning: A case study of practice at Otago Polytechnic, Dunedin, New Zealand [Unpublished DProfStudies (Adult Learning) thesis]. Middlesex University, London, UK.

Ker, P. (1993). Implementing procedures for the implementation of prior learning: Issues arising from a pilot programme at Auckland Institute of Technology. Paper presented at the NZQA RPL Conference, Wellington, NZ.

McDougall, J., \& Gunn, C. (1992). Recognising prior learning: Guidelines in policy development. Nelson, NZ: Nelson Polytechnic and the New Zealand Qualifications Authority.

McDrury, J., \& Alterio, M. G. (2002). Learning through storytelling: Using reflection and experience in higher education contexts. Palmerston North, NZ: Dunmore Press.

New Zealand Qualifications Authority. (1993a). Draft policy on the recognition of prior learning. Recognition of Prior Learning Conference, 2 I-23 April, Wellington, NZ.

New Zealand Qualifications Authority (1993b). Recognition of Prior Learning Conference, 21-23 April, Wellington, NZ.

Sheehan, D. ( 1992). Using the portfolio method for assessing prior learning [Unpublished report]. University of Canterbury, Christchurch, NZ. 